UDC 82-1/-9;930.85

Submitted: 21.07 .2018

LBC 63.3(0)4;80

Accepted: 20.09.2018

\title{
GENRE NATURE OF CHURCH CANONICAL CATECHISM BY THE PATRIARCH OF CONSTANTINOPLE NICHOLAS III GRAMMATIKOS ${ }^{1}$
}

\author{
Anton V. Anashkin \\ St. Tikhon's Orthodox University, Moscow, Russian Federation
}

\begin{abstract}
Introduction. The paper examines the genre genealogy of church canonical questions and answers by Patriarch of Constantinople Nicholas III Grammatikos. Genre determination of Byzantine catechism literature is a very important aspect of studying of the entire textual corpus in format of a series of question and answers. Although the rhetorical format of catechism was widespread in Byzantium in the 11th-15th cc., unfortunately, this topic is poorly studied. In addition, the literature in this format does not constitute a homogeneous corpus of texts. That is why genre nature of questions and answers is subtle.

Methods. Therefore, it necessitates a differentiated approach to every collection of catechism since the very solution of the problem is in the research of their content. Solution by means of method of text structural and compositional features' analysis allows sheding light on genre nature of other catechism collections.

Analysis and results. Canonical catechism by Nicholas Grammatikos has a complex manuscript tradition: there are seven editions of various Greek versions of the text available at the moment at our disposal. Considering this the total number of question-and-answer' units reaches 27. Based on analysis of the text structure, its content particularities and stylistics, the author comes to conclusion of the epistolary genesis of the monument. This finding should be taken into consideration in the further study of the Byzantine catechism.

Key words: Byzantine collections of questions and answers, Byzantine catechism literature, canonical and legal catechism, church correspondence, Nicholas III Grammatikos.

Citation. Anashkin A.V. Genre Nature of Church Canonical Catechism by the Patriarch of Constantinople Nicholas III Grammatikos. Vestnik Volgogradskogo gosudarstvennogo universiteta. Seriya 4, Istoriya. Regionovedenie. Mezhdunarodnye otnosheniya [Science Journal of Volgograd State University. History. Area Studies. International Relations], 2018, vol. 23, no. 5, pp. 25-33. (in Russian). DOI: https://doi.org/10.15688/ jvolsu4.2018.5.2
\end{abstract}

УДК $82-1 /-9 ; 930.85$

ББК $63.3(0) 4 ; 80$

Дата поступления статьи: 21.07.2018

Дата принятия статьи: 20.09.2018

\section{ЖАНРОВАЯ ПРИРОДА КАНОНИКО-ПРАВОВЫХ ОТВЕТОВ ПАТРИАРХА НИКОЛАЯ ІІ КИРДИНИАТА ГРАММАТИКА ${ }^{1}$}

\author{
Антон Владимирович Анашкин \\ Православный Свято-Тихоновский гуманитарный университет, г. Москва, Российская Федерация
}

\footnotetext{
Аннотация. Статья посвящена исследованию жанровой генеалогии текста канонических вопросоответов патриарха Константинопольского Николая III Кирдиниата Грамматика. Вопрос жанра памятников византийской канонической вопросоответной письменности является одним из главных при изучении корпуса текстов в форме эротапокризов, которая в Византии была особенно популярна в XI-XV веках. Степень изученности настоящей проблемы в целом необходимо признать низкой. Решение этого вопроса посредством исследования данных пे памятников методом анализа структурно-композиционных особенностей текста и его содержания представляется наиболее эффективным и может пролить свет на природу других собраний вопросоответных сборников.

Эротапокризы Николая Кирдиниата имеют сложную рукописную традицию: существует семь изданий различных греческих редакций текста, с учетом которых общее число вопросоответных пар достигает 27. На основе анализа содержания, структуры и языка текста автор приходит к заключению, что памятник имеет эпистолярный генезис.
} 


\section{ВИЗАНТИЙСКОЕ СВЕТСКОЕ И КАНОНИЧЕСКОЕ ПРАВО}

Ключевые слова: византийские вопросоответы, византийская эротапокритическая литература, канонико-правовые эротапокризы, церковная переписка, Николай III Грамматик.

Цитирование. Анашкин А. В. Жанровая природа канонико-правовых ответов патриарха Николая III Кирдиниата Грамматика // Вестник Волгоградского государственного университета. Серия 4, История. Регионоведение. Международные отношения. - 2018. - Т. 23, № 5. - С. 25-33. - DOI: https://doi.org/10.15688/ jvolsu4.2018.5.2

Введение. Канонические вопросоответы - один из самых слабоизученных жанров византийской церковной письменности. От больших юридических сводов эти незначительные по объему памятники прежде всего отличало то, что в них отражена реальная бытовая церковная действительность византийских селений (как правило, небольших городов или деревень) в период XI-XV веков. Российским ученым, в числе которых, прежде всего, необходимо упомянуть А.С. Павлова, А.И. Алмазова, В.Н. Бенешевича - специалистов в области церковного права, принадлежит честь первого научно-критического издания многих вопросоответных собраний.

В 1987 г. в Софии вышел 2-й том труда В.Н. Бенешевича (1871-1938 гг.) «Древнеславянская кормчая XIV титулов без толкований» $2^{2}$. В числе прочих текстов церковно-правового, исторического и теологического характера, помещенных в данном томе, содержит-

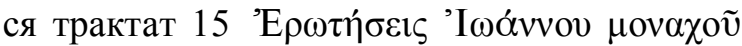

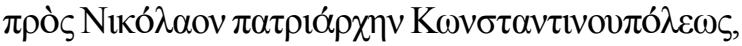
греческий текст которого сопровождается параллельным славянским переводом первых шести вопросоответов [5, с. 101-111]. Данный памятник византийской церковной каноникоправовой мысли имеет сложную рукописную традицию. В настоящий момент существует 7 изданий различных редакций текста ${ }^{3}$. Кроме того существует церковнославянский извод текста вопросоответов (в так называемой Екатерининской Кормчей книге 1787 г. $\left.^{4}\right)$. Несмотря на очевидную популярность памятника в церковно-канонической среде, сам текст остается слабо изученным. Настоящая работа посвящена исследованию жанровой природы канонических эротапокризов патриарха Константинопольского Николая ІІІ Кирдиниата Грамматика (1084-1111).

Методы. Проблема жанровой детерминации византийских эротапокризов определяется их неоднородностью по типу и содержанию, которая и составляет главную особен- ность корпуса текстов, носящих общее название вопросоответы ${ }^{5}$. К настоящему моменту сложилось несколько подходов к решению этой проблемы, из которых два по отношению друг к другу выступают антагонистическими (с точки зрения ее решения): вопросоответы как самостоятельный жанр (такой подход разделяли Г. Барди [10, p. 341-369], А. П. Каждан [16, p. 727], Л. Перроне [18, p. 485-505]) и вопросоответы как литературная форма (Х. Дёрри [13, S. 343-344], И. Пападояннакис [17, p. 91-92], А. Милтенова [8, с. 6], П. Ермилов $[14$, с. 110-111]). Предлагаемый нами подход заключается в исследовании, прежде всего, содержания текстов вопросоответов. Без использования метода структурно-композиционного анализа текста и анализа его содержания разрешение поставленной научной проблемы представляется малоэффективным. Примененный метод требует рассмотрения вопросоответов не в совокупности, но каждого отдельно. Результативность применения такого метода показало исследование текста канонических ответов Никиты Ираклийского (XII в.) $[4$, с. $56-58]$.

Анализ. Греческий текст канонико-правовых ответов в настоящем издании В.Н. Бенешевича [5, с. 101-111] представляет собой 19 вопросоответных блоков ${ }^{6}$. В каждом бло-

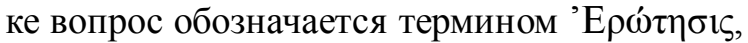
а ответ - терминами 'Ало́крібıৎ или $\Lambda$ б́бı. По содержанию блоки можно разделить на несколько тематических кластеров:

a) литургический: основная часть вопросоответных блоков (8) посвящена вопросам литургической практики и совершения богослужения вообще: $1,4,8$ - о посте; 2 - о нахождении монаха в алтаре; 3 - о коленопреклонении; 7, 14 - о вкушении антидора; 6 о причастии;

б) канонико-правовой (6): 5, 11 - о церковных дисциплинарных наказаниях (прещениях) и литургических правах низложенных священнослужителей; 9 - об оставлении мо- 
настыря; 16 - о месте погребения и перенесении останков покойных; о каноническом достоинстве Канонария (Псевдо-)Иоанна Постника и восьми апостольских книг Климента Римского ${ }^{7}$ - в вопросоответных блоках 15,18 ;

в) экзегетический: в вопросах 12, 13 вопроситель хочет получить разъяснение трудных для понимания мест из сочинений св. Василия Великого ${ }^{8}$;

г) внетематический: 10, 17, 19 - в них вопрошающая сторона просит прокомментировать различные нетривиальные казусы монастырского или приходского быта.

Структурно-композиционный анализ текста позволяет выделить в нем следующие элементы: преамбулу, содержащую приветствие и пояснительную записку к вопросам, и вопросоответные блоки - типичный для этого корпуса текстов принцип организации [2, c. $10 ; 3$, с. 15$]$. При этом то, что нами обозначено как преамбула, в издании В.Н. Бенешевича включено в 1-й вопросоответный

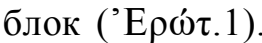

Результаты анализа текста преамбулы позволяют, на наш взгляд, говорить о том, что в его основе лежит переписка, на которую, прежде всего, могут указывать термины

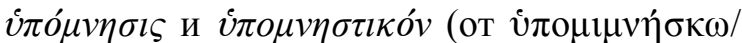

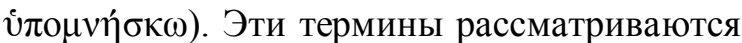
нами как termini technici, служащие для обозначения каких-либо записок и сообщений:

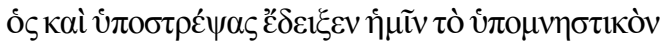

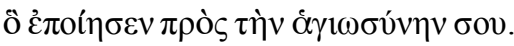

возвратившись, он показал нам записку, которую написал к твоей святости ${ }^{9}$.

В этом техническом значении термин v̇ó $\mu \nu \eta \sigma 1 \varsigma$ встречается, в частности, и в вопросоответах Илии Критского (нач. XII в.) $[6$, c. 32$]$ :

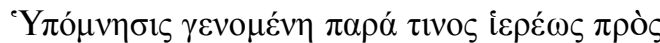

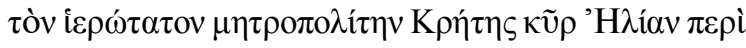
$\tau \tilde{\eta} \varsigma \pi \rho о \sigma \kappa о \mu \iota \delta \tilde{\eta} \varsigma$.

Записка, посланная от некоего иерея к святейшему митрополиту Критскому господину Илии относительно проскомидии.

В этой связи примечательным представляется наблюдение Л. Бургманна, который при исследовании дипломатической терминологии в Пире (сер. XI в.) отмечает [11, S. 464], что в этом юридическом сборнике судебных реше-

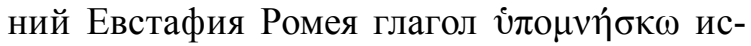
пользуется как terminus technicus в значении сообщать кому-то что-то ${ }^{10}$.

Кроме того, в первом по изданию В.Н. Бенешевича вопросе приводится сообщение о том, что вопрошающая сторона когда-то прежде уже направляла к патриарху Николаю некоего монаха с изложенными письменно вопросами:

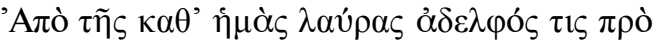
$\pi \mathrm{o} \lambda \lambda \tilde{\omega} v \dot{\eta} \mu \varepsilon \rho \tilde{\omega} v \dot{\alpha} \pi \varepsilon \sigma \tau \alpha \dot{\alpha} \lambda \eta \quad \pi \alpha \rho \dot{\alpha} \tau \tilde{\eta} \varsigma \dot{\eta} \mu \tilde{\omega} v$

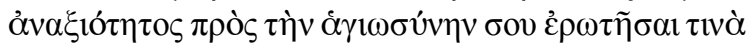

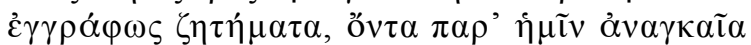
('Е

От нашей лавры один брат за много дней до этого был послан нашим недостоинством к твоей святости, дабы письменно спросить о некоторых вопросах, которые важны для нас.

Как оказалось, решение этих вопросов непонятно для вопрошающей стороны:

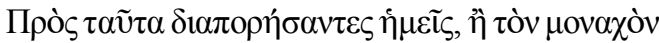

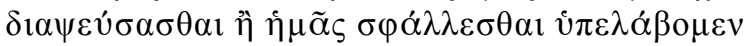

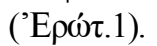

Этого не поняв, мы решили, что либо монах ошибся, либо мы заблуждаемся.

Конечно, эта предыстория может говорить о том, что все недоумения были представлены через некоего монаха сначала устно. И можно было бы также предположить, что вопросов при первичном обращении к Патриарху было лишь четыре и записаны они были несколько позднее. Однако же в первом ответе Патриарха обнаруживаем свидетельство (если и не прямое, то, по крайней мере, косвенное) имевшей место переписки: каі

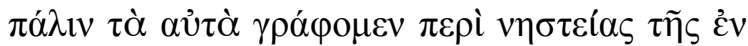
$\tau \varepsilon \tau \rho \alpha \delta о \pi \alpha \rho \alpha \sigma \kappa \varepsilon v \tilde{\eta}$ - «и снова то же самое пишем о посте в среду и пятницу» ('А $\pi .1)$.

Исследование вопросоответных блоков показывает, что с точки зрения внутреннего характера вопроса их можно дифференцировать по двум типам - общие и частные. В общих вопрошатель просит прокомментировать или найти решение по какому-либо общему вопросу церковной практики. Например:

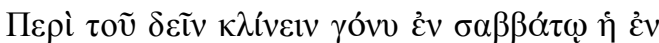

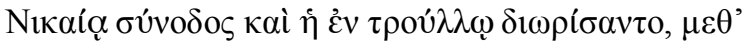




\section{ВИЗАНТИЙСКОЕ СВЕТСКОЕ И КАНОНИЧЕСКОЕ ПРАВО}

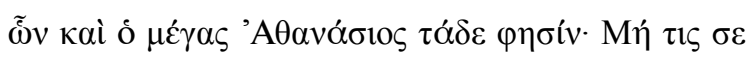

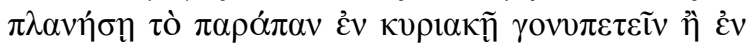

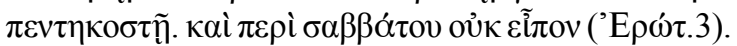

О том, что должно преклонять колена в субботу, постановили Никейский и Трулльский соборы, а между тем и Афанасий Великий говорит следующее: «Пусть никто не прельстит тебя преклонять колена вовсе: ни в воскресенье, ни в Пятидесятницу». А о субботе ничего не сказал.

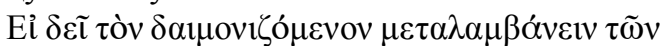

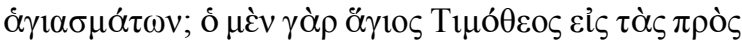

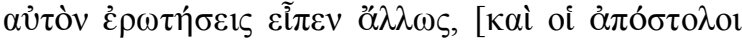

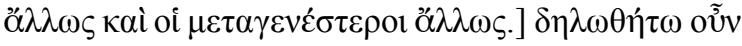

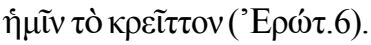

Следует ли беснующегося причащать Святых Таин, ибо св. Тимофей на вопросы, касающиеся этого, отвечал одно, [апостолы - другое, а следующие за ними - третье]. Итак пусть будет указано нам лучшее мнение.

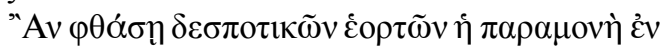

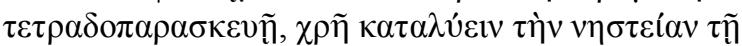

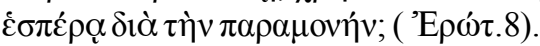

Если случится навечерие Господского праздника в среду или пятницу, нужно ли прекращать пост уже с вечера ради праздника?

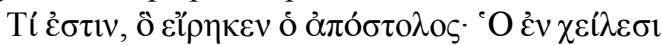

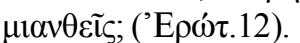

Что есть то, что сказал апостол: «Осквернившийся устами»?

Этим и им подобным вопросам общего плана, особенно важным не только с практической, но и с исторической точки зрения, как бы противостоят частные, где требуется разрешение какой-то частной, уникальной ситуации, не получившей прежде определенной канонической регламентации (ср. с ответами Никиты Ираклийского: [4, с. 57]). Как правило, это вопросы крайне специальные и потому для общецерковной практики во многом имеют маловажное значение. Но вот именно они и обращают на себя особое внимание при изучении истории памятника и исследовании его жанровой природы. Эти вопросы по сути представляют собой описание различных сюжетов византийского церковного быта, притом не гипотетических, а вполне определенных. Само содержание этих вопросов говорит о нетривиальности ситуации, в которой оказались ее участники, и отсутствии «стандартного» или, так сказать, линейного решения, которое - что особенно важно - вопрошающей стороне важно получить как можно скорее. Этот момент важен для характеристики памятника в целом: ведь в его задаче оказывается разрешение реальных проблем действительности и определение конкретных парадигм поведения. Так, ко второму типу можно отнести, например, вопросы 10 и 19:

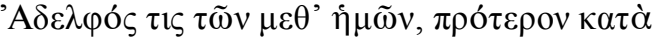

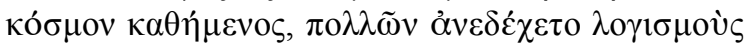

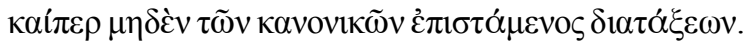

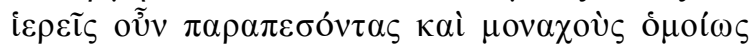

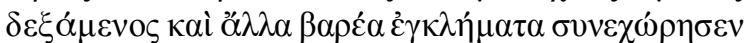

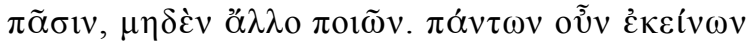

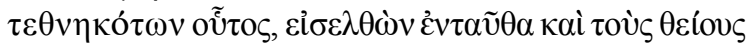

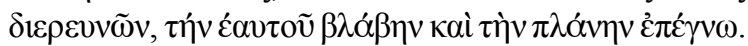

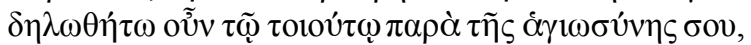

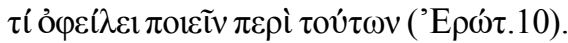

Один наш брат, прежде живший в миру, стал принимать (на исповеди. $-A$. A.) помыслы многих, хотя ничего не знал из канонических установлений. Поэтому, принимая падших священников и монахов, тяжкие вины всем прощал, не налагая никаких прещений. И вот, когда все они умерли, он, придя сюда и божественные каноны изучив, свою ошибку и заблуждение познал. Итак, пусть будет разъяснено твоею святостью, что должно делать в таких случаях [1, с. 103].

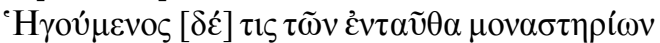

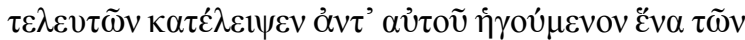

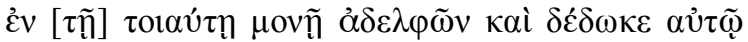

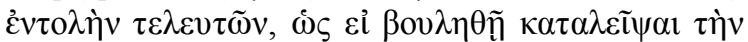

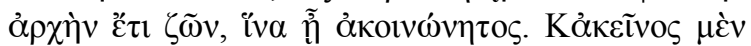

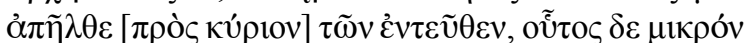

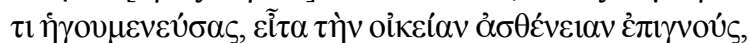

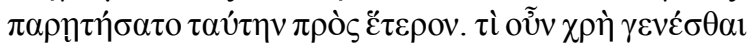

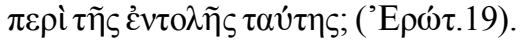

Один [же] игумен местных монастырей, умирая, поставил вместо себя игуменом одного из братии этой обители и, умирая, дал ему заповедь, что если он захочет передать власть, будучи еще живым, то пусть будет отлучен. И вот он отошел [ко Господу], а этот, пробыв немного игуменом и, затем, познав собственную немощь, попросил (передать) власть другому. Итак, что делать с этой заповедью?

Особенно интересным представляется то, что в виду отсутствия общецерковных установлений по какому-либо значимому вопросу ответы, которые изначально не претендовали быть законодательными постановлениями, в некоторых случаях позднее получали общецерковное признание как правовые нормы ${ }^{11}[9$, с. $380-381]$. И таким образом некоторые из них стали причиной формирования самостоятельных канонов, в основе которых 
лежали решения, предложенные в подобных вопросоответных собраниях. Так, в частности, произошло с ответом 19, на базе которого сформулировано отдельное дисциплинарное правило [20, p. 473]. Наряду с другими правилами патриарха Николая Грамматика (а также правилами патриархов Константинопольских свтт. Иоанна Постника и Никифора I Исповедника) оно включается в некоторые издания свода канонов в качестве приложения.

Наличие пусть и незначительного в отношении общего объема текста числа вопросов частного характера, на наш взгляд, нужно рассматривать как аргумент в пользу эпистолярного происхождения этого вопросоответного собрания [2, с. 12].

Из 19 вопросов четыре $(4-6,10)$ содержат персональную просьбу дать решение или объяснение неоднозначных случаев церковной практики. Вопросы 4, 6, 10 заканчиваются, а вопрос 5 начинается следующими фразами, вполне характерными для памятников этого

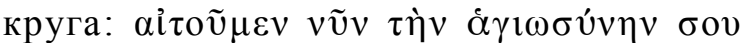

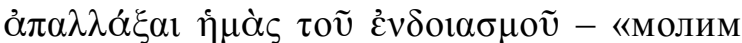
ныне твою святость избавить нас от сомнения» ('Е «хотим, чтобы было разъяснено и это»

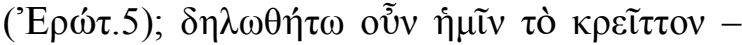
«итак пусть будет указано нам лучшее мне-

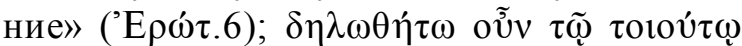

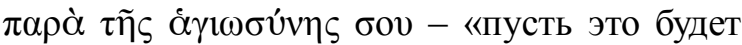
разъяснено твоею святостью» ('Е Имеющиеся в этих фразах формы глаголов и личных местоимений 1-го лица множествен-

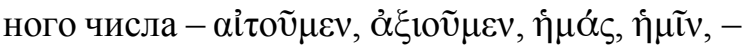
как мы полагаем, нужно рассматривать как «формальное» или этикетное множественное, а именно Pluralis modestiae. Кроме того, сличение наиболее раннего из известных нам списков текста по рукописи Vindob. jurid. gr. 11 (1191 г.) и списка текста, например, по рукописи Athen. EB 1372 (1311 г.), взятой в качестве основного в издании Афинской синтагмы Раллиса и Потлиса [21, б. 417-426], показывает, что первом из списков эти фразы сохранены, во втором же полностью отсутствуют в результате, очевидно, «редакторской» правки. Логичным объяснением исключения этих элементов из основного текста представляется отсутствие какой-либо их содержательной значимости. Таким образом, данное наблюдение, на наш взгляд, говорит о том, что перед нами реликты реально имевшей место эпистолярной коммуникации по различным церковно-практическим вопросам.

Отсутствие же тематического группирования вопросоответных блоков, их чередование по темам и повторение сюжетов, вероятнее всего, указывает на то, что эта коммуникация происходила в несколько этапов, о чем могут свидетельствовать отдельные фразы из 'Е

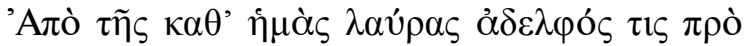
$\pi \mathrm{o} \lambda \lambda \tilde{\omega} v \dot{\eta} \mu \varepsilon \rho \tilde{\omega} v \dot{\alpha} \pi \varepsilon \sigma \tau \alpha \dot{\alpha} \lambda \eta \ldots \dot{\varepsilon} \rho \omega \tau \tilde{\eta} \sigma \alpha l \tau \imath \nu \grave{\alpha}$

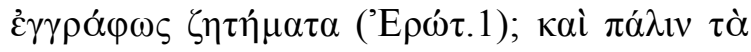

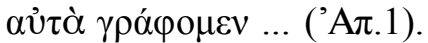

Примечательно и то, что в отдельных случаях можно наблюдать сохранение эпистолярных этикетных формул с личным местоимением 2-го лица в генитиве: $\delta$ о $\tilde{\lambda} о \varsigma \tau \tilde{\eta} \varsigma$

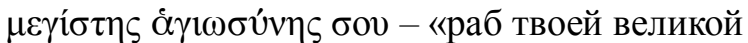

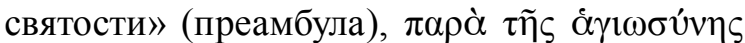

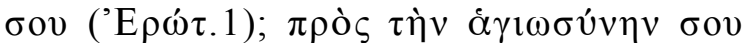

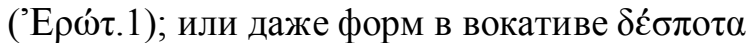
ő $\gamma 1 \varepsilon$ - «святый владыка» ('Е

Как известно, византийский эпистолярный жанр требовал довольно строгого формуляра - наличия преамбулы и заключительной части, между которыми располагался текст письма. Он, в свою очередь, мог стать самостоятельным литературным произведениям, полным развернутых сравнений и реминисценций из Священного Писания, античной и христианской литературы. Формуляру также подчинялись краткие деловые письма, а правила их написания излагались в специальных письмовниках. Несмотря на то, что преамбула в канонических ответах, как и обычные для писем заключительные клаузулы, нередко вообще отсутствует, приведенные нами эпистолярные «реликты» могут свидетельствовать именно в пользу эпистолярного генезиса памятников. Создание более поздних редакций текстов последующими переписчиками было, как известно, свойственно и для византийских, и для западных литературных произведений Средневековья - к переписываемому тексту относились творчески, да и сама проблема авторства понималась иначе, чем в Новое время. Конечно, едва ли следует стремиться строго определить место канонических ответов в византийской письменности, тем более 


\section{ВИЗАНТИЙСКОЕ СВЕТСКОЕ И КАНОНИЧЕСКОЕ ПРАВО}

что границы жанров нередко оказываются размытыми. Однако же несомненно то, что мы имеем дело с жанровой трансформацией (акты живой коммуникации, реализовавшейся в форме дистанционного диалога, а точнее деловой корреспонденции, застывают и позднее кодифицируются как собрание прецедентов - по сути, церковно-практическое руководство или справочник) и что текст канонических вопросоответов патриарха Николая III Грамматика имеет своим прототипом деловые письма.

Результаты исследования. Итак, в результате исследования текста канонико-правовых ответов патриарха Николая III Кирдиниата Грамматика можно заключить, что в его основе лежит реально имевшая место переписка по церковно-практическим вопросам, на основании следующих сделанных нами наблюдений: форма и организация текста, напоминающие корреспонденцию; наличие вопросов специального характера с просьбой найти решение для какой-либо уникальной ситуации ввиду отсутствия общецерковной канонической регламентации (так называемые частные вопросы); присутствие технических терминов

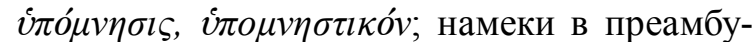
ле и 1-м вопросоответном блоке на перепис-

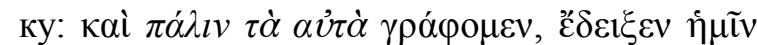

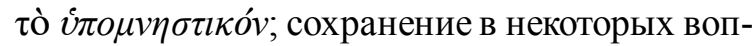
росоответных парах этикетного множественного (Pluralis modestiae) $\alpha i \tau o \tilde{v} \mu \varepsilon v$,

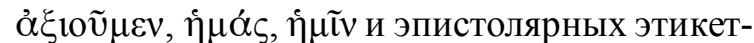

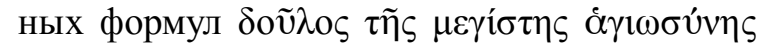
боv, $\delta \varepsilon \dot{\sigma \pi о \tau \alpha ~ \alpha ̊ \gamma 1 \varepsilon ~ и ~ д р . ~}$

\section{ПРИМЕЧАНИЯ}

${ }^{1}$ Статья подготовлена в рамках проекта «Статус первенствующих престолов в раннехристианской и византийской традиции» при поддержке Фонда Развития ПСТГУ.

2 Публикацию этого сборника памятников канонического права В.Н. Бенешевич начал готовить в рамках издания полного корпуса православных церковно-правовых текстов в нач. XX в. Однако исторические события 1917 г., аресты Бенешевича в 1922 и 1928 гг., пятилетняя ссылка в Ухту в 1931 г., новый арест в 1937 г. и расстрел в 1938 г. воспрепятствовали реализации этого проекта. В 1964 г. Академией наук СССР была начата работа по завершению труда Бенешевича. Подготовка к печати и до- работка издания были осуществлены Я.Н. Щаповым, Ю.К. Бегуновым и И.С. Чичуровым. Подробнее см. в публикации [7, с. 240-243].

${ }^{3}$ Издания эти следующие (располагаем их в хронологической последовательности): Canon.

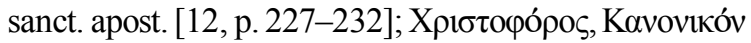

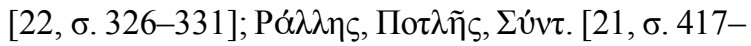
426] (по Athen. ЕВ 1372, которая представляет собой копию более ранней рукописи 1311 г. - Istanbul Serail 115); Pitra, Spic. Sol. [20, p. 477-480] (по Paris. 364 f. 60-63, Coisl. 39 f. 277-280, по Paris. 1321 f. 457-

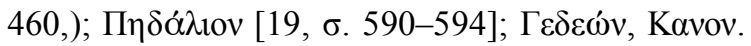

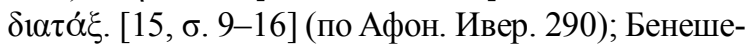
вич, ДСК [5, с. 101-111] (по Vindob. jurid. gr. 11 л. 47а

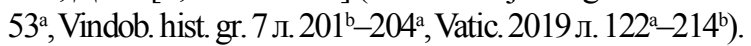

${ }^{4}$ См. в Екатерининской Кормчей Ч. 1, гл. 53, с. ГЛА (331). Считаем также необходимым указать на наличие других славянских переводов текста в Рязанском (1284 г.) и Печском (1585 г.) списках Кормчей сербской редакции.

5 Так, среди византийских церковных вопросоответов обыкновенно выделяют следующие пять разновидностей: экзегетико-догматические, аскетические, катехизические, полемические и каноникоправовые [8, с. 8-12]. Вместе с тем нужно отметить, что подобная система описания или классификация вопросоответных собраний по типам во многом носит условный характер, поскольку с точки зрения содержания эти типы могут пересекаться друг с другом.

${ }^{6}$ Если учитывать разночтения всех редакций, которые отражены в перечисленных выше изданиях, то общее число уникальных вопросоответных блоков достигает 27 [1, с. 87-88].

${ }^{7}$ Имеется в виду сборник апостольских постановлений в восьми книгах, который приписывался сщмч. Клименту Римскому. Памятник обладал крупным авторитетом на Востоке вплоть до XIX в., о чем свидетельствует огромное число рукописей (в настоящий момент установлено 15 только независимых друг от друга).

${ }^{8}$ Речь идет о Третьем каноническом послании к епископу Амфилохию Иконийскому ('Е робнее см.: [1, с. 104-105].

9 Здесь и далее в статье все переводы с греческого выполнены автором, если не оговорено иное. Греческий текст приводится по изданию В.Н. Бенешевича, которое было подготовлено им преимущественно по рукописи Vindobonensis jurid.gr. 11. В квадратных скобках [] приводятся вставки греческого текста по другим рукописям Vindob.hist.gr. 7 л. $201^{\mathrm{b}}-204^{\mathrm{a}}$ и Vatic. 2019 л. $122^{\mathrm{a}}$ $214^{\mathrm{b}}$, в круглых же () приводятся вставки в русский перевод, которые необходимы, по мнению автора настоящей статьи, для лучшего понимания текста. 
${ }^{10}$ В Peira. XV 12 приводится упоминание об одном судебном деле, которое Евстафию поручил Иоанн (?) Орфанотроф. Во время судебного процесса Евстафий попросил его сообщить (Ǐv

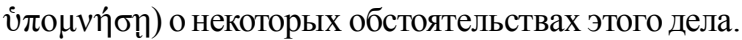

11 На это, в частности, указывает то, что многие вопросоответники включались в различные правовые сборники.

\section{СПИСОК СОКРАЩЕНИЙ}

\author{
'A

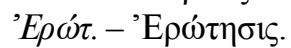 \\ ПЭ - Православная энциклопедия. \\ $O D B$ - The Oxford Dictionary of Byzantium. \\ $R A C$ - Reallexikon für Antike und Christentum. \\ $R B$ - Revue Biblique.
}

\section{СПИСОК ЛИТЕРАТУРЫ}

1. Анашкин, А. В. Канонические «Ответы» патриарха Константинопольского Николая III Грамматика (1084-1111) : Содержание, источники, история текста / А. В. Анашкин // Вестник ПСТГУ. Сер. III, Филология. - 2013. - № 2 (32). - С. 87-113.

2. Анашкин, А. В. Проблемы жанра вопросоответной литературы в контексте церковно-канонической письменности поздневизантийского периода / А. В. Анашкин // Вестник ПСТГУ. Сер. III, Филология. - 2014. - № 4 (39). - C. 7-16. - DOI: https:// doi.org/10.15382/sturIII201439.7-15.

3. Анашкин, А. В. Жанровые и языковые особенности византийских канонических вопросоответов XI-XV вв. : автореф. дис. ... канд. филол. наук / Анашкин Антон Владимирович. - М., 2015. - 28 с.

4. Анашкин, А. В. Эпистолярные «следы» в византийских церковных канонико-правовых эротапокризах XII в. (на материале канонических ответов митрополита Никиты Ираклийского) / А. В. Анашкин // Вестник Костромского государственного университета. - 2017. - № 2 (25). - С. 56-59.

5. Бенешевич, В. Н. Древнеславянская кормчая XIV титулов без толкований. Т. II / В. Н. Бенешевич ; подгот. Я. Н. Щапов, Ю. К. Бегунов, И. С. Чичуров. - София : Изд-во БАН, 1987. - 332 с.

6. Желтов, М. С., диак. Вопросоответы митрополита Илии Критского : Свидетельство об особенностях совершения Божественной литургии в нач. XII века / диак. Михаил Желтов, М. М. Бернацкий // Вестник ПСТГУ. Сер. I, Богословие. Философия. -2005 . - №. 14. - С. 23-53.

7. Кузенков, П. В. Книжника «Великого книжника антиохийского возглашение о календах, нонах и идах»: трактат о римских древностях в древнесла-

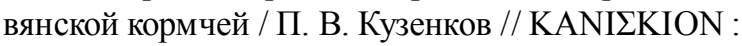

Юбилейный сборник в честь 60-летия профессора Игоря Сергеевича Чичурова. - М. : Изд-во ПСТГУ, 2006. - C. 240-279.

8. Милтенова, A. Erotapokriseis : Съчиненията от кратки въпроси и отговори в старобългарската литература / А. Милтенова. - София : Дамян Яков, 2004. $-580 \mathrm{c}$.

9. Цыпин В., прот. Каноническое право / прот. В. Цыпин [и др.] // ПЭ. Т. 30. - М. : ЦНЦ «Православная энциклопедия», 2012. - С. 367-421.

10. Bardy, G. La littérature patristique des “Quaestiones et Responsiones” sur l'Écriture Sainte/ G. Bardy // RB. - 1932. - № 41 (3). - P. 341-369.

11. Burgmann, L. Zur diplomatischen Terminologie in der Peira / L. Burgmann // Zwischen Polis, Provinz und Peripherie : Beiträge zur byzantinischen Geschichte und Kultur. - Wiesbaden : Harrasowitz Verl., 2005. - S. 457-467.

12. Canones sanctorum apostolorum, conciliorum generalium et prouincalium sanctorum patrum epistola canonica. Nomocanon cum commentariis Balsamonis. Electronic data. - Parisiis : Typ. Regiis, 1620. - 1134 p. Mode of access: https://babel.hathitrust.org /cgi/pt?id=ucm. 5319079576; view=1 up;seq=259;size=75 (date of access: 20.07.2018). - Title from screen.

13. Dörrie, H. Erotapokriseis / H. Dörrie, H. Dörries // RAC. - 1966. - Bd. 6. - S. 343-344.

14. Ermilov, P. Towards a Classification of Sources in Byzantine Question-and-Answer Literature / P. Ermilov // Theologica Minora. The Minor Genres of Byzantine Theological Literature. - Turnhout : Brepols, 2013. - P. 110-125. - (Byzantios ; 8). - DOI: https://doi.org/10.1484/M.SBHC-EB.1.101921.

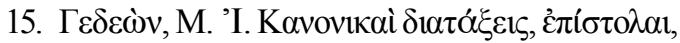

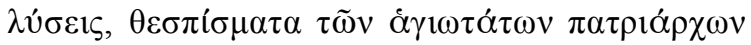

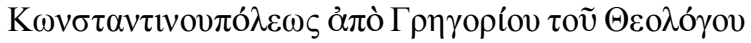

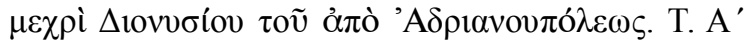

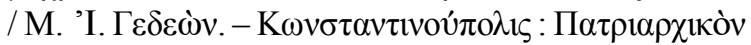
Tvл., 1888. $-422 \sigma$.

16. Kazhdan A. Erotapokriseis / A. Kazhdan // ODB. Vol. 1. - New York; Oxford : Oxford Univ. Press, 1991.- P. 727.

17. Papadoyannakis, Y. Instruction by Question and Answer : The Case of Late Antique and Byzantine Erotapokriseis / Y. Papadoyannakis // Greek Literature in Late Antiquity: Dynamism, Didactism, Classicism. Hampshire: Mauke, 2006. - P. 91-105.

18. Perrone, L. Sulla preistoria delle "quaestiones" nella letteratura patristica. Presupposti e sviluppi del genere letterario fino al IV sec. / L. Perrone// Annali di storia dell'esegesi. - 1991. - T. 8. - P. 485-505.

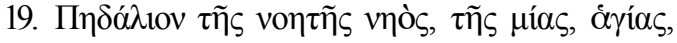

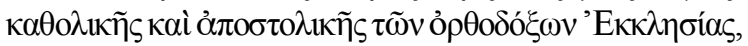

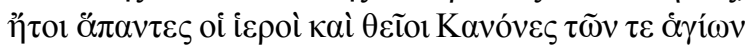

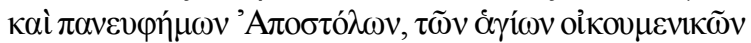

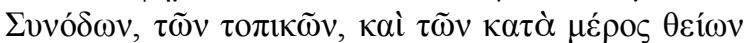




\section{ВИЗАНТИЙСКОЕ СВЕТСКОЕ И КАНОНИЧЕСКОЕ ПРАВО}

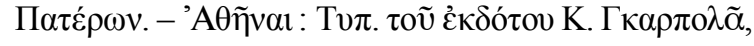
1886. $-648 \sigma$.

20. Pitra, J. B. Spicilegium Solesmense complectens sanctorum patrum scriptorumque ecclesiasticorum anecdota hactenus opera, selecta e graecis orientalibusque et latinis codicibus, publici juris facta curante domno J. B. Pitra o.s.b. monacho e congregatione gallica, nonnullis ex abbatia Solesmensi opem conferentibus. T. 4 / J. B. Pitra. - Parisiis : Firmin Didot, 1858. $-608 \mathrm{p}$.

21. Pó $\lambda \lambda \eta \varsigma, \Gamma$. 'A. $\Sigma u ́ v \tau \alpha \gamma \mu \alpha \tau \tilde{\omega} v \theta \varepsilon i ́ \omega v \kappa \alpha i ̀ ~ i \varepsilon \rho \tilde{\omega} v$

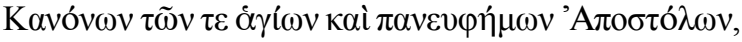

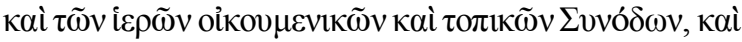

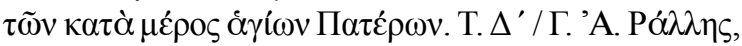

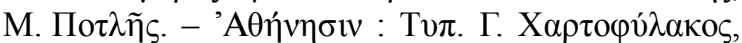
1854. $-660 \sigma$.

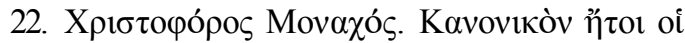

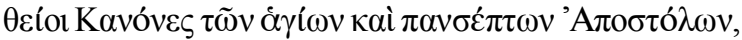

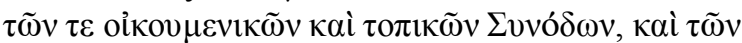

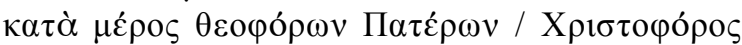

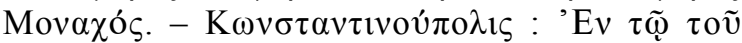

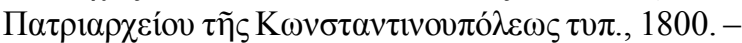
$451 \sigma$.

\section{REFERENCES}

1. Anashkin A.V. Kanonicheskie "Otvety" patriarkha Konstantinopolskogo Nikolaya III Grammatika (1084-1111): soderzhanie, istochniki, istoriya teksta [Canonical "Answers" of Patriarch of Constantinople Nicholas III the Grammarian (10841111): Content, Sources, Text History]. Vestnik PSTGU. Seriya III, Filologiya [St. Tikhon's University Review. Series III: Philology], 2013, vol. 2/32, pp. 87-113. (in Russian).

2. Anashkin A.V. Problemy zhanra voprosootvetnoy literatury $\mathrm{v}$ kontekste tserkovnokanonicheskoy pismennosti pozdnevizantiyskogo perioda [Genre Problems of Question-and-Answer Literature in the Context of Late Byzantine Canonical Writing]. Vestnik PSTGU. Seriya III, Filologiya [St. Tikhon's University Review. Series III: Philology], 2014, vol. 4 (39), pp. 7-16. DOI: https://doi.org/10.15382/ sturIII201439.7-15. (in Russian).

3. Anashkin A.V. Zhanrovye i yazykovye osobennosti vizantiyskikh kanonicheskikh voprosootvetov $X I-X V$ vv.: avtoreferat dissertatsii [Genre and Linguistic Features of Byzantine Church Canonical Questions and Replies of the $11^{\text {th }}-15^{\text {th }}$ centuries: Abstract of a Candidate's Thesis]. Moscow, 2015. 28 p. (in Russian).

4. Anashkin A.V. Epistolyarnye "sledy" v vizantiyskikh tserkovnykh kanoniko-pravovykh erotapokrizakh XII v. (na materiale kanonicheskih otvetov mitropolita Nikity Irakliyskogo) [Epistolary
"Traces" in Byzantine Church Canonical Erotapokriseis of the $12^{\text {th }}$ century (on the material of canonical catechism by Nicetas metropolitan of Heraclea)]. Vestnik Kostromskogo gosudarstvennogo universiteta [Vestnik of Kostroma State University], 2017, vol. 2 (25), pp. 56-59 (in Russian).

5. Beneshevich V.N. Drevneslavyanskaya kormchaya XIV titulov bez tolkovaniy [The Old Slavonic Pilot Book of Fourteen Titles without Commentaries]. Vol. II. Sofia, Izd-vo BAN, 1987. 332 p. (in Russian)

6. Zheltov M.S., deacon, Bernatsky M.M. Voprosootvety mitropolita Ilii Kritskogo: Svidetelstvo ob osobennostyakh soversheniya Bozhestvennoy liturgii v nach. XII veka [Questions and Answers of Elias, Metropolitan of Crete: a Testimony of Byzantine Liturgical Practice in the Beginning of the $12^{\text {th }} \mathrm{c}$.]. Vestnik PSTGU. Seriya I, Bogoslovie. Filosofiya [St. Tikhon's University Review. Series I: Theology, Philosophy], 2005, vol. 14, pp. 23-53. (in Russian).

7. Kuzenkov P.V. "Velikogo knizhnika antiokhiyskogo vozglashenie o kalendakh, nonakh i idakh": traktat o rimskikh drevnostyakh v drevneslavyanskoy kormchey ["Invocation of the Great Antiochian Scribe on the Calends, the Nones and the Ides": a Treatise on Roman Antiquities in the Old Slavonic Pilot Book]. KANISKION: Yubileynyy sbornik $v$ chest 60-letiya professora Igorya

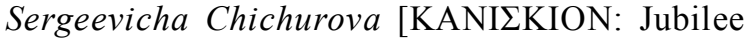
Collection in Honor of the $60^{\text {th }}$ Birthday of Prof. I.S. Chichurov], Moscow, Izd-vo PSTGU, 2006, pp. 240279. (in Russian).

8. Miltenova A. Erotapokriseis. Sachineniyata ot kratki vaprosi $i$ otgovori $v$ starobalgarskata literatura [Erotapokriseis. Short Questions and Responses in Old Bulgarian Literature]. Sofia, Damyan Yakov Publ., 2004. 580 p. (in Bulgarian).

9. Tsypin V., archpriest, et al. Kanonicheskoe pravo [The Canon Law]. Pravoslavnaya entsiklopediya [Orthodox Encyclopedia]. Vol. 30. Moscow, Pravoslavnaya entsiklopediya Publ., 2012, pp. 367-421. (in Russian).

10. Bardy G. La litérature patristique des “Quaestiones et Responsiones” sur l'Écriture Sainte. Revue Biblique, 1932, no. 41 (3), pp. 341-369.

11. Burgmann L. Zur diplomatischen Terminologie in der Peira. Zwischen Polis, Provinz und Peripherie: Beiträge zur byzantinischen Geschichte und Kultur, Wiesbaden, Harrasowitz Verl., 2005, pp. 457-467.

12. Canones sanctorum apostolorum, conciliorum generalium et prouincalium, sanctorum patrum epistolae canonicae. Nomocanon cum commentariis Balsamonis. Parisiis, Typ. Regiis, 1620. 1134 p. URL: https://babel.hathitrust.org/cgi/ pt?id=ucm.5319079576; ;iew $=1$ up; seq $=259 ;$ size $=75$ (accessed 20 July 2018). 
13. Dörrie H., Dörries H. Erotapokriseis. RAC, 1966, vol. 6, pp. 343-344.

14. Ermilov P. Towards a Classification of Sources in Byzantine Question-and-Answer Literature. Theologica Minora. The Minor Genres of Byzantine Theological Literature. Turnhout, Brepols, 2013, pp. 110-125. (Byzantios; vol. 8). DOI: https://doi.org/ 10.1484/M.SBHC-EB.1.101921.

15. Gedeōn M. I. Kanonikai diataxeis, epistolai, lyseis, thespismata, tōn agiōtatōn patriarhōn Kōnstantinoupoleōs apo Grēgoriou tou Theologou mexri Dionysiou tou apo Adrianoupoleōs [Canonical Decrees, Letters, Decisions, Resolutions of the Holy Patriarchs of Constantinople from Gregory the Theologian to Dionysius of Adrianople]. Vol. I. Constantinople, Patriarhikon Typ. Publ., 1888. 422 p. (in Greek).

16. Kazhdan A. Erotapokriseis. ODB. Vol. 1. New York; Oxford, Oxford Univ. Press, 1991. 727 p.

17. Papadoyannakis Y. Instruction by Question and Answer: the Case of Late Antique and Byzantine Erotapokriseis. Greek Literature in Late Antiquity: Dynamism, Didactism, Classicism. Hampshire, Mauke, 2006, pp. 91-105.

18. Perrone L. Sulla preistoria delle "quaestiones" nella letteratura patristica. Presupposti e sviluppi del genere letterario fino al. IV sec. Annali di storia dell'esegesi, 1991, vol. 8, pp. 485-505.

19. Pēdalion tēs noètēs nēos, tēs mias, agios, katholikēs kai apostolikēs tōn orthodoxōn Ekklēsias, ètoi apantes oi ieroi kai theioi kanones tōn agiōn kai paneufēmōn Apostolōn, ton agiōn oikoumenikōn Synodōn, tōn topikōn, kai tōn meros theiōn Paterōn
[The Rudder (Pedalion) of the Metaphorical Ship of the One Holy Catholic and Apostolic Church of the Orthodox Christians, or all the Sacred and Divine Canons of the Holy and Renowned Apostles, of the Holy Councils, Ecumenical as well as Regional, and of Individual Fathers]. Athens, Typ. Tou ekdotou K. Gkarpola Publ., 1886. 648 p. (in Greek).

20. Pitra J.B. Spicilegium Solesmense complectens sanctorum patrum scriptorumque ecclesiasticorum anecdota hactenus opera, selecta e graecis orientalibusque et latinis codicibus, publici juris facta curante domno J. B. Pitra o.s.b. monacho e congregatione gallica, nonnullis ex abbatia Solesmensi opem conferentibus. Vol. 4. Paris, Firmin Didot, 1858. 608 p.

21. Rallēs G.A., Potlēs M. Syntagma tōn theiōn kai ierōn Kanonōn tōn agiōn kai paneufemōn Apostolōn, kai tōn ierōn oikoumenikōn kai topikōn Sunodōn, kai tōn kata meros agiōn Paterōn [Syntagma of the Divine and Sacred Canons of the Holy and Renowned Apostles, of the Holy Councils, Ecumenical as well as Regional, and of Individual Fathers]. Vol. 4. Athens, Typ. G. Hartofylakos Publ., 1854.660 p. (in Greek)

22. Hristoforos Monahos. Kanonikon ètoi oi theioi Kanones tōn agiōn kai panseptōn Apostolōn, tōn te oikoumenikōn kai topikōn Synodōn, kai ton kata meros theoforōn Paterōn [Kanonikon, or the Divine Canons of the Holy and Renowned Apostles, of the Councils, Ecumenical as well as Regional, and of Individual God-Bearing Fathers]. Constantinople, En ō $\tau$ tou Patriarheiou tēs Kōnstantinoupoleōs typ. Publ., 1800. 451 p. (in Greek).

\section{Information about the Author}

Anton V. Anashkin, Candidate of Sciences (Philology), Deputy Dean for Research, Faculty of Theology, Senior Lecturer of Department of Ancient Languages and Literature, St. Tikhon's Orthodox University, Novokuznetskaya St., 23B, 115184 Moscow, Russian Federation, miles-an@rambler.ru, https://orcid.org/0000-0002-5246-2210

\section{Информация об авторе}

Антон Владимирович Анашкин, кандидат филологических наук, заместитель декана богословского факультета по научной работе, старший преподаватель кафедры древних языков и древнехристианской письменности богословского факультета, Православный Свято-Тихоновский гуманитарный университет, ул. Новокузнецкая, 23Б, 115184 г. Москва, Российская Федерация, miles-an@rambler.ru, https://orcid.org/0000-0002-5246-2210 